\title{
Факторы, влияющие на размер премии за контроль
}

\author{
Родионов И.И. ${ }^{29}$, Перевалова К.А. ${ }^{30}$
}

Вопросы введения и установления размера премий и скидок за контрольный характер пакета акиий относятся к фундаментальным проблемам оценки стоимости бизнеса. Размер премии за контроль может значительно повлиять на рыночную стоимость оцениваемого бизнеса или пакета акиий. В каждом конкретном случае размер премии за контроль зависит от множества специфических для каждого вида бизнеса факторов: внутренних особенностей, таких как удельный вес оцениваемого пакета акиий, степень концентрачии акционерного капитала, режим голосования, и внешних, таких как правовая форма предприятия или законодательные ограничения. Данная статья посвящена обзору и анализу этих и других факторов, которые прямо или косвенно влияют на размер премии за контрольный характер пакета акций.

\section{JEL: G32, G34}

\section{Ключевые слова на русском: контроль, премии, скидки, факторы, пакет акций}

Многие специалисты в области оценки считают, что использование в рамках оценки бизнеса или пакета акций данных о «среднерыночной» премии за контроль без учета специфики конкретной сделки некорректно. Существует множество факторов, которые могут оказать значительное влияние на размер премии за контроль. «Практически никто не ставит под сомнение тот факт, что владелец миноритарного пакета акций компании не обладает ценными прерогативами контроля и потенциальными экономическими выгодами, которые имеет владелец контрольного пакета. Однако разницу в стоимости акций миноритарного и контрольного пакетов, которая отражала бы наличие или отсутствие этих прерогатив и вытекающих из них выгод, очень трудно определить в количественном выражении. Кроме того, эта разница значительно варьируется в зависимости от совокупности фактов и обстоятельств, связанных с конкретной компанией и конкретными акционерами» (Пратт, 2001). В настоящей статье будут рассмотрены основные и наиболее интересные факторы, которые оказывают влияние на размер премии за контроль.

\section{Наличие/отсутствие у пакета элементов контроля}

Международные стандарты оценки определяют премию за контроль как дополнительную стоимость, присущую контрольному пакету акций по сравнению с миноритарной долей, отражающую дополнительные полномочия по управлению компанией. Если покупатель приобретает только часть акций компании, то стоимость приобретаемого им пакета, скорее всего, будет меньше, чем соответствующий процент от общей стоимости всех акций. В экономической литературе говорится об основных элементах контроля, которые обуславливают то, что «стоимость владения (распоряжения) контрольным пакетом всегда больше стоимости владения (распоряжения) миноритарным пакетом». Среди основных из них (Pratt and Reilly, 2000) можно назвать права: назначать или менять состав менеджмента и совета директоров; определять размеры вознаграждений топ-менеджеров; определять текущую производственную и стратегическую политику, менять направления развития бизнеса; осуществлять приобретение, аренду или ликвидацию активов бизнеса, включая установки, недвижимость и оборудование; выбирать поставщиков, продавцов и

\footnotetext{
29 Д-р эконом. наук, профессор кафедры экономики и финансов фирмы НИУ ВШЭ.

${ }^{30}$ Аспирант НИУ ВШЭ, ЗАО «Евроэксперт», оценщик.
} 
субподрядчиков; вести переговоры и осуществлять поглощения и слияния; ликвидировать, распускать, продавать или рекапитализировать компанию; продавать или приобретать казначейские облигации; регистрировать акции компании для первоначального или вторичного публичного размещения.

\section{Удельный вес пакета акций}

Расчет корректировок, к которым относится премия за контроль, как правило, ведется на последнем этапе оценки стоимости бизнеса. Для определения премии за контроль, первоначально необходимо выяснить, какой пакет планируется к продаже. Согласно международным стандартам оценки пакеты акций делятся на два вида: контрольный (мажоритарный) и неконтрольный (миноритарный). К миноритарный долям относятся все доли, которые имеют менее 50\% голосующих акций компании. В российской практике действующее законодательство не определяет понятия контрольного и миноритарного пакетов. Суть их можно установить исходя из требований ст. 6 Федерального закона «Об акционерных обществах». В соответствии с данной статьей, контроль над акционерным обществом (AO) может осуществляться в случае наличия факта преобладающего участия в его уставном капитале, дающего возможность его участникам определять решения, принимаемые таким обществом. Возможны следующие варианты:

- Полный контроль (свыше 75\%).

- Абсолютный контроль (75\%). Пакет акций от 75\% и выше дает держателю возможность принимать любые решения в отношении управления компанией. «Абсолютный контроль представляет собой неограниченную способность владельцев доли в акционерном капитале осуществлять все права, связанные с использованием собственности, включая право на ликвидацию компании» (Фишмен, Пратт, 2000).

- Операционный контроль (50\% + 1 акция). «Под операционным контролем понимается способность владельцев доли собственности в акционерном капитале выбирать большинство членов совета директоров» (Фишмен, Пратт, 2000). Решающий размер пакета (от 50 до 75\%) дает акционеру массу преимуществ по управлению компанией.

- Блокирующий пакет $(25 \%+1$ акция). Владелец $25 \%$ пакета акций имеет право заблокировать ряд существенных решений, а также имеет право доступа к документам бухгалтерского учета.

- Дополнительные возможности (10\%). Мелкий пакет до 10\% собственного капитала не дает значительных преимуществ по контролю.

Размер пакета акций определяет выбор методов в рамках конкретных подходов, которые будут использованы в оценке, и их значимость при взвешивании результатов и расчете итоговой величины стоимости.

Блокирующий или крупный миноритарный пакет по сравнению с миноритарным обычно имеет премию. Однако эта премия будет, несомненно, меньше премии за контрольный пакет. Есть и исключения: если миноритарный пакет способствует контролю над предприятием, то такой пакет акций заслуживает не скидку, а премию (Десмонд, Келли, 1996).

В случае пакета акций менее 100\% наличие миноритарных акционеров, способных предпринять определенные действия, направленные против осуществления некоторых прерогатив контроля, способно снизить величину премии за контроль.

«Пакеты акций в размере 50\% не являются ни контрольными, ни миноритарными. Владельцы 50\%-ной доли обычно могут препятствовать принятию корпоративных решений, но не могут повлиять на осуществление компанией каких-либо действий. Стоимость 50\%-ной доли обычно находится где-то посередине между стоимостью контрольного пакета акций и стоимостью миноритарного пакета в чистом виде. При этом эмпирические данные, которые могли бы послужить ориентиром при определении размера скидки на 50\%-ную долю в компании со стоимости контрольного пакета акций или премии к стоимости миноритарного 
пакета, отсутствуют. Тем не менее можно отметить, что с учетом недостаточной степени контроля на 50\%-ные доли иногда начисляется скидка со стоимости контрольного пакета акций в размере $15 \%$.

В некоторых обстоятельствах наличие двух 50\%-ных долей в одной компании не означает, что их владельцы лишены права контроля в равной мере. Такая ситуация может сложиться в случае, если один из владельцев обладает некоторыми прерогативами контроля в соответствии с положениями договора. В этом случае скидка со стоимости контрольного пакета акций должна быть меньше для доли, владелец которой обладает некоторыми контрольными полномочиями, и выше для доли, владелец которой такими полномочиями не обладает» (Пратт, 2001).

\section{Эффект распределения собственности / степень концентрации акционерного капитала}

При определении скидок и надбавок к оцениваемому пакету акций оценщику следует понять, с каким пакетом он имеет дело и как на его стоимость влияют величины неоцениваемых пакетов акций. При проведении анализа структуры акционерного капитала необходимо учитывать ряд факторов (Раева, Ковалев, 2007):

1) простое увеличение числа акций в пакете дает преимущество (фактор количества);

2) укрупнение миноритарного пакета акций уменьшает преимущества других аналогичных пакетов (фактор перераспределения);

3) дополнительные преимущества контрольного пакета акций достигаются за счет потери преимуществ миноритарных пакетов (фактор баланса);

4) группа пакетов акций при их объединении имеет преимущества, равные по меньшей мере сумме преимуществ каждого из пакетов (фактор объединения);

5) увеличение количества мелких пакетов при отсутствии контрольного пакета уменьшает общую величину премии (фактор распыленности);

6) приближение двух (или более) пакетов к размеру контрольного пакета обостряет конкурентную борьбу и увеличивает преимущества мелких миноритарных пакетов (фактор конкуренции).

Для определения влияния степени концентрации акционерного капитала на уровень контроля рассматриваемого пакета акций необходимо сгруппировать предприятия по числу акционеров, владеющих оставшейся частью акционерного капитала, и величине их пакетов акций. По этим признакам можно выделить следующие формы распределения капитала:

- распыление - все эмитированные акции распределены среди множества акционеров, каждый из которых владеет не более $2 \%$ акций;

- низкая концентрация капитала - остальными акциями владеют мелкие акционеры, пакет акций в руках одного акционера не превышает 10\%;

- средняя концентрация - оставшейся частью акционерного капитала владеют мелкие и средние акционеры, пакет акций в руках одного акционера составляет от 10 до 25\%;

- высокая концентрация - несколько акционеров, каждый из которых владеет от 25 до $50 \%$ акций;

- сверхвысокая концентрация - в руках одного акционера сосредоточено свыше 50\% акций.

Так как пакет акций размером менее $10 \%$ не обладает контролем, а уровень контроля $75 \%$ пакета акций всегда является абсолютным, в таблице 1 уточняется влияние концентрации капитала на степень контроля остальных пакетов акций. Данные таблицы 1 позволяют предположить, что рыночная стоимость различных пакетов будет колебаться в зависимости от концентрации акционерного капитала, которая может ограничивать или увеличивать степень контроля акционера владельца соответствующего пакета акций, а следовательно, влиять на размер премии за контрольный пакет акций. 


\begin{tabular}{|c|c|c|c|c|}
\hline \multirow{2}{*}{$\begin{array}{c}\text { Распределение } \\
\text { оставшейся } \\
\text { части } \\
\text { акционерного } \\
\text { капитала }\end{array}$} & \multicolumn{4}{|c|}{ Пакет акций } \\
\hline & $10-25 \%$ & $\begin{array}{c}25 \%+1 \text { акция } \\
\text { до } 30 \%\end{array}$ & $\begin{array}{c}\text { 30\%+1 акция } \\
\text { до } 50 \%\end{array}$ & $\begin{array}{c}50 \%+1 \text { акция } \\
\text { до } 75 \%\end{array}$ \\
\hline Распыление & \multirow{2}{*}{$\begin{array}{c}\text { Уровень контроля от } \\
\text { мнннмального до } \\
\text { абсолютного }\end{array}$} & \multirow{2}{*}{$\begin{array}{c}\text { Уровень контроля от } \\
\text { незначительного до } \\
\text { абсолютного }\end{array}$} & \multirow{3}{*}{$\begin{array}{c}\text { Уровень контроля } \\
\text { то высокого до } \\
\text { абсолютного }\end{array}$} & \multirow{4}{*}{$\begin{array}{l}\text { Уровень контроля } \\
\text { от операцнонного } \\
\text { до абсолютного }\end{array}$} \\
\hline $\begin{array}{l}\text { Низкая } \\
\text { концентрация }\end{array}$ & & & & \\
\hline $\begin{array}{l}\text { Средняя } \\
\text { концентрация }\end{array}$ & $\begin{array}{c}\text { Уровень контроля от } \\
\text { мнннмального до } \\
\text { незначнтельного }\end{array}$ & \multirow{3}{*}{$\begin{array}{c}\text { Уровень контроля от } \\
\text { незначительного до } \\
\text { высокого }\end{array}$} & & \\
\hline $\begin{array}{l}\text { Высокая } \\
\text { концентрация }\end{array}$ & \multirow{2}{*}{$\begin{array}{c}\text { Уровень контроля } \\
\text { может быть } \\
\text { незначнтельным }\end{array}$} & & $\begin{array}{l}\text { Уровень контроля } \\
\text { до операцнонного }\end{array}$ & \\
\hline $\begin{array}{l}\text { Сверхвысокая } \\
\text { концентрация }\end{array}$ & & & $\begin{array}{c}\text { Уровень контроля } \\
\text { до высокого }\end{array}$ & \\
\hline
\end{tabular}

Анализ структуры акционерного капитала позволяет определить величины премий для каждого из пакетов акций в определенном сочетании с другими пакетами.

\section{Финансовые условия бизнеса и финансовые показатели компании-цели}

К финансовым условиям бизнеса относятся: финансовая структура капитала, уровень финансового левериджа, схемы финансирования, применяемые на предприятии, например лизинг, и т.п.). Если финансовое положение компании неустойчивое, то многие права, связанные с контролем (например, право на покупку контрольных пакетов акций других компаний), становятся трудно реализуемыми.

Как показывают исследования различных авторов, финансовые показатели компаниицели влияют на размер уплачиваемой премии.

1. Рост выручки компании-цели (положительная зависимость), увеличение объема рынка (положительная зависимость) и отношение собственного капитала к активам (отрицательная зависимость) (Rhoads, 1987).

2. Степень финансового рычага, ликвидности и потенциальное повышение стоимости активов (Crawford, Lechner, 1996).

3. Доходность собственного капитала компании-цели (положительная зависимость) (Rose, 1987).

4. Отношение долга к активам, величина чистого оборотного капитала, соотношение рыночной и балансовой стоимости (Walkling, Edmister, 1985).

\section{Страновые различия: законодательство, степень защищенности прав мелких акционеров, наличие конкурентной среды}

Примером многочисленных исследования в области отличий премий за контроль между странами является исследование Неновы (Nenova, 2000). Международные различия объясняются различием в системе законодательства и уровнем защиты инвесторов. В странах Северной Америки, которые используют обычное право, премия за контроль ниже за счет более жесткого законодательства, которое регулирует получение частных выгод. Максимальное усиление давления законодательства приводит к сокращению премии за контроль на $31 \%$, при усилении защиты акционеров падение составляет $20 \%$, ужесточение правил, регулирующих слияния и поглощения, - 8\% (Nenova, 2000).

Для Канады, Северной Африки, Англии, Америки и скандинавских стран премия за контроль составляет менее $10 \%$ (в Финляндии очень близка к нулю). В Мексике наблюдаются максимальные значения премии за контроль - от 46 до 51\% (Dragota, 2006).

Также, в странах с более развитой конкуренцией, независимой прессой, лучшими 
стандартами отчетности и высоким выполнением налоговых требований премия за контроль ниже. Результатами исследования Зингалеса стали следуюшие данные: разброс медианных значений премии за контроль составляет от $-4 \%$ для Японии до 65\% для Бразилии (Dyck, Zingales, 2002).

Во многих странах существует практика нарушения прав миноритарных акционеров. Среди наиболее распространенных нарушений можно выделить нарушение права на получение информации, на участие в управлении обществом, на получение дивидендов, а также увод активов и разводнение капитала. Средняя стоимость контрольного пакета в странах с сильной защитой мелких инвесторов, таких как США, составила 4,5\%, а в странах Континентальной Европы, с более слабой защитой прав миноритарных акционеров, - 25,4\% (Nenova, 2000).

Зингалес обнаружил, что премия за контроль американских компаний составляет 4\%, а итальянских - 30\%. «Поскольку ценность контроля - это просто приведенная оценка частных выгод, получаемых главным акционером, то их сумма, а значит, и ценность контроля зависит от степени защищенности прав мелких акционеров. В разных странах эта защищенность различна. Без строгих и подробных законов об отчетности (disclosure rules) крупным инвесторам легче скрывать злоупотребления, следовательно, легче извлекать выгоду из своего положения» (Зингалес, 1998).

Данное явление характерно не только для развивающихся, но и для развитых рынков капитала. Это подтверждается исследованиями, осуществленными Ла Порта в 1996-1998, 2000 годах.

Существуют также формы поведения руководителей корпораций, когда они используют средства компании для оплаты своих привилегий. Это их частные выгоды. В умеренных формах такое поведение встречается довольно часто, особенно в тех странах, где такое поведение не считается незаконным, как, например, во Франции: в это стране «закон не обязывает руководителей корпораций использовать все корпоративные ресурсы в интересах только корпорации» (Dyck, Zingales, 2002).

K тому же следует отметить то, что даже когда закон существует, он может оказаться неисполнимым. В некоторых странах запрещена оплата адвокатов по результатам процесса. В итоге мелкие акционеры не могут оплатить судебное преследование руководителей корпораций.

На премию за контроль влияют также: развитость рынков капитала (чем она меньше, тем выше премия за контроль), уровень развития СМИ, уровень развития налоговой системы (Шмелев, 2006).

Правовое пространство, действующие законы, механизмы защиты инвесторов, правила регулирования слияний и поглощений, уставы корпораций объясняют $68 \%$ межстрановых отличий в стоимости контрольного пакета (Nenova, 2000).

\section{Эффект недобросовестного поведения менеджеров}

Если целью сделки является максимизация своего благосостояния менеджерами компания-покупателя, это приводит к конфликту между менеджерами и акционерами компании-покупателя, эффективность сделки M\&A снижается. Данное обстоятельство отражается на размере премии за контроль.

Фирт в своем исследовании использует теорию агентских издержек (Firth, 1980). Исследование показало, что сделки слияний и поглощений представляют собой довольно легкий путь к получению выгод акционерами приобретенных фирм и менеджерами компаний-покупателей за счет быстрого роста компании. Однако такие сделки противоречат интересам акционеров компании-покупателя, и они несут потери.

В 1986 году Дженсен сформулировал одну из теорий мотивации сделок M\&A, которая сейчас известна как теория агентских издержек свободных потоков денежных средств (Agency Theory of Free Cash Flow) (Jensen, 1986). По Дженсену, менеджмент склонен к 
заключению сделок M\&A в количестве, существенно отличающемся от оптимального. За счет роста компании менеджмент усиливает свою значимость для акционеров, влияние на развитие компании, что, по сути, делает его незаменимым, а значит, и снижает вероятность увольнения. Автор выдвигает гипотезу о так называемой «контрольной функции долга». Привлечение долга и необходимость его обслуживания будет стимулировать менеджмент компании на долгосрочное развитие, а не на получение краткосрочных выгод в виде завышенных представительских расходов. Инвестиции в активы, которые имеют ценность для компании только при наличии конкретного менеджмента, были также широко рассмотрены в работе Шляйфера и Вишни (Shleifer, Vishny, 1989).

\section{Наличие конкурентов при борьбе за компанию-цель (модели борьбы за контроль)}

По данным ряда исследований (Slusky, Caves, 1991; Varaiya, 1987), фактор существования конкурентов-покупателей оказался весьма значимым. Относительное влияние данного фактора было также получено Уоклингом и Эдмистером и составило 33,5\% (Walkling, Edmister,1985).

\section{Тип акционерного общества}

Исследование авторов (Ang, Kohers, 2001) посвящено вопросу о разнице в размере премий для открытых и закрытых компаний. В своем исследовании они попытались оценить премию за контроль в закрытых компаниях при помощи соотношения price-to-book ratio. Такой подход, по мнению авторов, вероятнее всего приводит к некоторым смещениям в оценке размера премии, поскольку балансовая стоимость активов очень часто занижается с целью снижения налогов на имущество. Тем не менее были получены следующие результаты: премия за контроль у закрытых компаний существенно выше, нежели у открытых компаний.

\section{Порядок голосования и принятия решений в компании}

\section{Кумулятивное голосование}

Мажоритарная система голосования - голосование на общем собрании акционеров по принципу «одна голосующая акция общества - один голос». Мажоритарная система голосования дает возможность обладателю большинства акций полностью контролировать результаты голосования. При кумулятивном голосовании число голосов, принадлежащих каждому акционеру, умножается на число лиц, которые должны быть избраны в совет директоров общества, и акционер вправе отдать полученные таким образом голоса полностью за одного кандидата или распределить их между двумя и более кандидатами. Кумулятивное голосование не обеспечивает автоматического представительства миноритарных акционеров в совете директоров; для избрания нужного директора миноритарные акционеры должны владеть долей в компании в минимальном установленном размере, а также должны складывать свои голоса по акциям так, как это необходимо. Кумулятивное голосование может увеличить размер скидки на контрольный пакет акций в связи с отсутствием полного контроля (Пратт, 2001).

\section{Требования в отношении квалифицированного большинства (Пратт, 2001)}

Для принятия определенных решений, например решений о ликвидации компании посредством распродажи ее активов или о слиянии с другой компанией, в ряде компаний, в соответствии с законодательством, уставом или внутренними правилами и регламентом своей деятельности, требуется наличие большего числа голосов, чем то, которое предоставляется пакетом акций в размере $50 \%$ плюс одна акция. 
Если пакет акций предоставляет право контроля над определенными действиями компании, но его размер недостаточен для принятия решений относительно ее других действий, то стоимость такого пакета акций будет находиться где-то в промежутке между стоимостью пакета, предоставляющего полный контроль над компанией, и стоимостью миноритарного пакета акций в чистом виде.

Если отправной точкой при оценке служит стоимость контрольного пакета акций, то применение той или иной скидки за отсутствие абсолютного контроля обычно является правомерным. Эмпирические исследования, которые помогли бы определить размер этой скидки, отсутствуют, но обычно ее размер находится в пределах от 5 до $15 \%$.

Для пакета акций, предоставляющего блокирующие полномочия, начисляется определенная премия к стоимости миноритарного пакета акций в чистом виде. Поскольку такие полномочия используются достаточно редко, размер премии, как правило, является довольно небольшим - возможно, в пределах от 5 до 15\%. Эта премия может начисляться на стоимость миноритарного пакета акций, активно продаваемых и покупаемых на рынке (до применения скидки за низкую ликвидность), или же, в случае использования стоимости контрольного пакета акций в качестве базы, она может быть отражена в более низком размере скидки за недостаточную степень контроля.

Таким образом, если существует вероятность того, что объем пакета акций может предоставлять его владельцу право оперативного, но не абсолютного контроля, или же если он может дать такому владельцу блокирующие полномочия, то оценщик должен изучить соответствующие законодательные акты, устав, внутренние правила и регламент деятельности компании, с тем чтобы определить, следует ли рассмотреть применение скидки или премии, обусловленной этими характеристиками.

\section{Типы собственников и их инвестиционные мотивы}

Группировки по категориям доминирующих собственников позволяют уточнить, в руках каких групп акционеров находятся рычаги контроля и какими возможностями для его осуществления они располагают. Предполагается следующая группировка предприятий по категориям доминирующих собственников (Синогейкина, 2002):

- Менеджеры и аутсайдеры. В России, как правило, представляют интересы крупных акционеров и игнорируют интересы прочих собственников.

- Государство. Являясь акционером, имеет значительные возможности управления предприятием и контроля над его деятельностью, мелкие и средние акционеры получают возможность реализовывать их законные права по управлению деятельностью общества.

- Работники. Являются миноритарными акционерами в обществах с распыленным капиталом. Контроль осуществляют представители мелких акционеров, при этом учитываются интересы и права всех акционеров.

При оценке рыночной стоимости пакетов акций необходимо учитывать мотивы потенциального инвестора, в зависимости от которых он преследует различные цели, а значит, по-разному оценивает права, предоставляемые акцией. Мотивы определяются целями инвестора: краткосрочные означают временное вложение финансовых ресурсов; долгосрочные означают то, что инвестор приобретает значительный пакет акций, получает возможность консолидировать отчетность и признавать компанию как дочернюю с целью осуществления контроля над деятельностью.

\section{Наличие привилегированных акций и государственного пакета акций}

Наличие в оцениваемом пакете привилегированных акций может повлиять на его ликвидность и контроль при выплате дивидендов. Выплата дивидендов уменьшает число голосующих акций в пакете на количество привилегированных акций. Соответственно уменьшается значимость пакета акций. При отсутствии выплат дивидендов все акции в 
пакете (обыкновенные и привилегированные) являются голосующими, соответственно увеличивается значимость пакета акций (Яскевич, 2004).

Государственный пакет акций может быть в составе пакетов ОАО и ЗАО. Госпакет можно отнести к «пассивному»: его владелец не будет стремиться к захвату контроля над предприятием и покупке дополнительных пакетов акций; в ближайшее время можно ожидать проведения аукциона по продаже этого пакета; кроме того, при миноритарном пакете государственных акций имеется большая вероятность его блокирования владельцем максимального удельного веса пакета или коалицией акционеров (Раева, Ковалев, 2007).

\section{Контактные ограничения}

Если долговые обязательства компании существенны, то это может ограничивать дивидендные выплаты и т.д. Здесь часть стоимости премии за контроль теряется, так как акционер не может реализовать имеющийся у него контроль для получения возврата на инвестированные средства.

\section{Размер вознаграждения генерального директора компании}

Зингалес в 1984-1990 годах провел исследование цен акций тех американских компаний, которые имели два класса обыкновенных акций с одинаковыми имущественными правами, но с разными правами голоса. В этом исследовании была обнаружена положительная зависимость величины премии от размера вознаграждения генерального директора компании. Вознаграждение сверх среднего уровня Зингалес относит к разновидности личных выгод, которые извлекает менеджер. В ходе его исследования оказалось, что на счет различий в вознаграждении можно отнести около $30 \%$ колебаний в величине премии за контроль (Чиркова, 2005).

\section{Тип сделки и способ оплаты}

Сделки M\&A делятся на горизонтальные, вертикальные и конгломератные. Эффективность последнего типа сделок вызывала серьезные научные дискуссии.

В 1997 году Хэйли, Пэлепу и Рубэк на основании выборки из 50 крупнейших сделок M\&A промышленных корпораций США (за период с 1979 по 1984 год), поделив все сделки на стратегические или финансовые, попытались определить, какие из них более прибыльные. Стратегические сделки - это дружественные сделки компаний одной отрасли, связанные производственной цепочкой. Финансовые сделки (конгломеративные) - это враждебные сделки компаний разных отраслей.

Результаты исследования показали, что чем меньше были связаны между собой корпорация-покупатель и корпорация-цель, тем менее прибыльной оказывалась сделка. Это объясняется значительно более высокой средней премией, которая в них уплачивалась (42\% против 29\%). Кроме того, конгломеративное поглощение, как правило, оплачивается на $100 \%$ денежными средствами (стратегические - обыкновенными акциями), что также можно записать ему в минус. На практике большой процент конгломеративных поглощений враждебные сделки, что также является причиной меньшей доходности (Рудык, 2005).

Уэнсли, Лейн и Янг (Wansley, Lane, Yang, 1983), в ходе своего исследования обнаружили, что способ оплаты сделки влияет на величину премии даже в большей степени, нежели тип сделки М\&А. В случае оплаты денежными средствами величина премии будет выше величины премии при оплате сделки ценными бумагами. Это влияние обусловлено прежде всего налоговыми последствиями для покупателя. Эти выводы также подтверждаются результатами исследования Хэйли, Пэлепу и Рубэка, приведенными выше.

Условия продажи способны значительно повлиять и на риск, и на прибыль участников сделки. Способ оплаты денежными средствами является в целом более простым и прямым, 
нежели способ оплаты акциями.

\section{Право назначать директоров в соответствии с договором}

Иногда владельцу пакета акций может быть предоставлено право назначать одного или нескольких директоров, закрепленное договором. Такое право часто предоставляется в рамках проектов венчурного финансирования. В этом случае, скидка за недостаточную степень контроля может быть снижена (Пратт, 2001).

В заключение следует отметить, что значимость каждого фактора может сильно меняться от компании к компании, от сделки к сделке. В дальнейшем представляется возможным сделать их условную классификацию для типов бизнеса (в виде таблицы) и прежде всего в сопоставлении с долей интеллектуального капитала в бизнесе. Также существует перечень факторов (база для применения премии за контроль; методы оценки бизнеса (пакета акций) и премии за контроль; цель оценки; отраслевая принадлежность и пр.; а также сопоставление понятий «премия за синергию» и «премия за финансовый контроль»), которые в рамках данной статьи отразить не представляется возможным, так как их обзор является темой отдельной статьи.

\section{Список литературы}

1. Зингалес Л. Финансы / пер. с англ. М., 1998.

2. Пратт Ш. П. Оценка бизнеса (анализ и оценка закрытых компаний) М.: Международная академия оценки и консалтинга, 2001.

3. Раева И.В., Ковалев С.Ю. Методы определения премии за контроль при оценке пакетов акций российских предприятий // Менеджмент сегодня. 2007. № 1.

4. Рудык Н.Б. Конгломератные слияния и поглощения: Книга о пользе и вреде непрофильных активов: учебное пособие. М.: Дело, 2005. С. 63.

5. Синогейкина Е. Г. Классификация пакетов акций и анализ их влияния на стоимость // Вопросы оценки. 2002. № 4. С. 39-52.

6. Чиркова Е.В. Как оценить бизнес по аналогии: Методологическое пособие по использованию сравнительных рыночных коэффициентов при оценке бизнеса и ценных бумаг. М.: Альпина Бизнес Букс, 2005.

7. Шмелев. М Премия за контроль сибирских компаний // Рынок ценных бумаг. № 7 от 17 апреля 2006 г.

8. Фишмен Дж., Пратт Ш.П. и др. Руководство по оценке стоимости бизнеса. М.: ЗАО «Квинто-Консалтинг», 2000.

9. Яскевич Е. Е., Анализ факторов, обуславливающих введение скидок и надбавок для оцениваемых пакетов акций (долей) [Электронный pecypc]. URL: http://www.appraiser.ru/default.aspx?SectionId=188\&Id=1333.

10. Ang, J., Kohers, N. (2001), The take-over market for privately held companies: the US experience, Cambridge Journal of Economics, 25 (2001) 723-748.

11. Crawford, D., Lechner, T. (1996), Takeover Premiums and Anticipated Merger Gains in the U.S. Market for Corporate Control, Journal of Business, Finance \& Accounting, 23 (1996) 807-829.

12. Dragota, V. (2006), Control Premiums for Rumanian listed companies. Bucharest Academy of Economic Studies, the Institute for Business and Public Administration from Bucharest. Romania: ASEBUSS.

13. Dyck, A., Zingales, L. (2002), Private Benefits of Control: An International, Comparison, Working Paper, Cambridge. URL: http://www.nber.org/papers/w8711.

14. Firth, M. (1980), Takeovers, Shareholder Returns, and the Theory of the Firm, The Quarterly Journal of Economics, 94(2) (1980) 235-260. 
15. Jensen, M. C. (1986), Agency Costs of Free Cash Flow, Corporate Finance, and Takeovers, American Economic Review, 76(2) (1986).

16. Nenova, T. (2000), The Value of Corporate Votes and Control Benefits: A Cross - Country Analysis. URL: http://ssrn.com/abstract $=237809$.

17. Pratt, S.P., Reilly, R.F., Schweis, R.P. (2000), Valuing Business, 4lh ed. New York: McGraw-Hill. P. 347-348.

18. Rhoads, S. (1987) Determinants of Premiums Paid in Bank Acquisitions. Atlanta Economic Journal, 15 20-27.

19. Rose, P. (1987), The Impact of Mergers in Banking. Journal of Economics and Business, 39 (1987) 289-312.

20. Pratt, S.P., (2001), Business Valuation Discounts and Premiums. Wiley.

21. Shleifer, A., Vishny, R. (1989), Management Entrenchment: The Case of Manager-Specific Investments, Journal of Financial Economics 25 (1989) 123-139.

22. Slusky, A.R., Caves R.E. (1991), Synergy, Agency, and the Determinants of Premia Paid in Mergers, The Journal of Industrial Economics, 39(3) (1991) 277-296.

23. Varaiya, N.P. (1987), Determinants of Premiums in Acquisition Transactions, Managerial and Decision Economics, 8(3) (1987) 175-184.

24. Walkling, R., Edmister, R. (1985), Determinants of Tender Offer Premiums, Financial Analysts Journal, (1985) 27-37.

25. Wansley, J.W., Lane, W.L., Yang, H.C. (1983), Abnormal Returns to Acquired Firms by Type of Acquisition and Method of Payment, Financial Management, 12(3) (1983) 16-22. 